\title{
Best Cloud Provider Selection using Integrated ANP-DEMATEL and Prioritizing SMI Attributes
}

\author{
Vahid Ghafori \\ Research Scholar, \\ Dept. of Applied Computer Science, \\ UITM, Rzeszow, Poland,
}

\author{
Reza Manouchehri Sarhadi \\ Research Scholar, \\ Dept. of Applied Computer Science, \\ UITM, Rzeszow, Poland,
}

\begin{abstract}
The adoption of cloud computing depends upon detailed comparison of cloud provider alternatives with careful consideration. Therefore, poor cloud provider selection can lead to failure in service delivery, compromise data confidentiality and data integrity and loss of meeting clients' demands. Cloud provider selection is a multi criteria decision making problem, which is based on considering various quantitative and qualitative factors to analyze criteria simultaneously.
\end{abstract}

The Analytic Network Process (ANP) is an advance and relatively new Multi Criteria Decision Making (MCDM) approach which can cope with many interactions between quantitative and qualitative criteria systematically. Furthermore, Decision Making Trial and Evaluation Laboratory (DEMATEL) technique is able to adjust the cause and effect relations among the criteria into a visual structural model along with applying the interdependencies within a series of criteria. However, both ANP approach and DEMATEL techniques in their single forms are not adequate to capture the uncertainty during value judgment deduction.

In this study, to overcome this problem, a new and effective decision making framework based on integrating ANP and DEMATEL is proposed for multi criteria decision making about best cloud computing provider selection in uncertain conditions.

\section{Keywords:}

Cloud computing, cloud provider selection, MCDM, ANP, DEMATEL.

\section{INTRODUCTION}

Many organizations have started lunching applications on cloud infrastructure and making their businesses agile by using flexible and elastic cloud services. But moving data and/or applications into the cloud is not straight forward. Many challenges exist to leverage the full potential of cloud computing [1]. Although many of these challenges related to application requirements and characteristics, other than that, choosing right cloud provider between numerous cloud provider offers becomes extremely difficult [2]. Therefore, given the variety of cloud service offering, a substantial challenge for organizations is to realize who the "best" cloud provider is that able to fulfill their business needs.

Cloud Service Measurement Index Consortium (CSMIC) at Carnegie Mellon University Silicon Valley has classified measurement indexes for assess and compare business services regardless of whether that service is internally provided or sourced from an outside company [3]."

In this study, we are moving the work of the consortium one step forward by using indexes as a selection criteria and proposing a framework that can compare and select the best cloud offer among different cloud providers in accordance with criteria priorities based on user requirements. In this framework we are using Decision Making Trial and Evaluation Laboratory and interview with experts, managers and specialists in IT management field. Each expert is asked to indicate the degree to which he or she believes a factor $\mathrm{i}$ affects factor $\mathrm{j}$. Moreover, to select cloud provider based on these criteria we propose an Analytical Network Process (ANP) based on ranking mechanism to resolve the problem of assigning weights to indexes for determining the relationship of the degree of interdependencies among them. Often, cloud customers have two types of operational and non-operational requirements. For making decision about which provider matches best with all operational and non-operational requirements, this framework can be used as a management dashboard [4].

\section{PROBLEM STATEMENT}

Typically the problems related to provider selection are two types [5]. The first type is single sourcing, in which a cloud provider is able to carry out all customers' needs including resource provisioning and quality of service (QoS). In this type the management only needs to decide which cloud provider is the best in regard to criteria priorities?

The second type is multiple sourcing, in which a cloud provider alone cannot meet all needs of cloud customer and customer must meet their demands through several providers. Management in this type of problems must take two different decisions. First, which providers are the best in regard to criteria priorities? And second, what services should be outsourced to each provider?

In many cases, organizations often choose only one provider for their services, they must compare services, performance and price from different providers during period of time. Therefore, in this article we discuss how to overcome provider selection problem in the state of single sourcing [6]

Selecting best provider, as a critical decision in IT management is significantly important, because it can lead organization in different industry to use systematically formed models to select providers and assign services to them. Therefore, the framework, within the domain of Information Technology can also support variety of decision-making 
scenarios based on the selected criteria to support the framework.

\section{REVIEW OF PROVIDER SELECTION METHODS}

The problem of provider selection is not relatively new. Appropriate provider selection is one of the basic strategies for improving the efficiency of any organization, which has a direct affect on the growth, reputation and profitability of the organization

Today, Information Technology management attempts to obtain the long-term participation with providers and uses fewer but more reliable ones. Thus, choosing right providers is something more than just simply looking at the list of providers' offering. For that reason, several methods have been proposed to resolve provider selection problem such as: Analytic Hierarchy Process (AHP), Genetic Algorithm (GA), Artificial Neural Networks (ANN), Data Envelopment Analysis (DEA), Fuzzy Set Theory, Data Envelopment Analysis (DEA), Case-Based Reasoning (CBR), Simple Multi-Attribute Rating Technique (SMART), Analytical Network Process (ANP) and mixed techniques [5].

\section{METHODOLOGY}

In this study, the framework is accomplished in four steps. At first, among SMI, set of attributes in categories are selected, then, through interview with the experts and decision makers the degree of interdependent relationship between different criteria is determined by the expert group in second step. Later, at third and forth step in order to compute the weight of each attribute and final ranking of desired providers to select the best one, integrated ANP-DEMATEL techniques were used to answer the main research question which is how to select best cloud provider. The process of the framework is illustrated in Figure 1.

\section{SERVICE MEASUREMENT INDEX (SMI)}

As briefly described before, Cloud Service Measurement Index Consortium (CSMIC) at Carnegie Mellon University Silicon Valley has classified measurement indexes as "set of business-relevant Key Performance Indicators (KPI's) to provide a standardized method for measuring and comparing a business service regardless of whether that service is internally provided or sourced from an outside company [3] ." From a practical standpoint, SMI enables customers of IT business services to perform "apples-to-apples" comparisons so they can make informed decisions about selecting specific services and service providers [7]. The SMI Framework provides a comprehensive view into the entire customer experience for cloud service providers in six primary areas: Quality, Agility, Risk, Capability, Cost and Security [8]. These categorize are demonstrated in Figure 2.

\section{DESIGNING A MODEL FOR ANP}

In regard to this research goal, at first we attempt to design proper network process model based on SMI criteria and subcriteria in Super Decision software. Table 1, shows criteria selected and symbolized for the ANP model in Super Decision software.

Because in this research we use the assessment of more than one expert, geometric mean technique is used to prioritize their point of view.

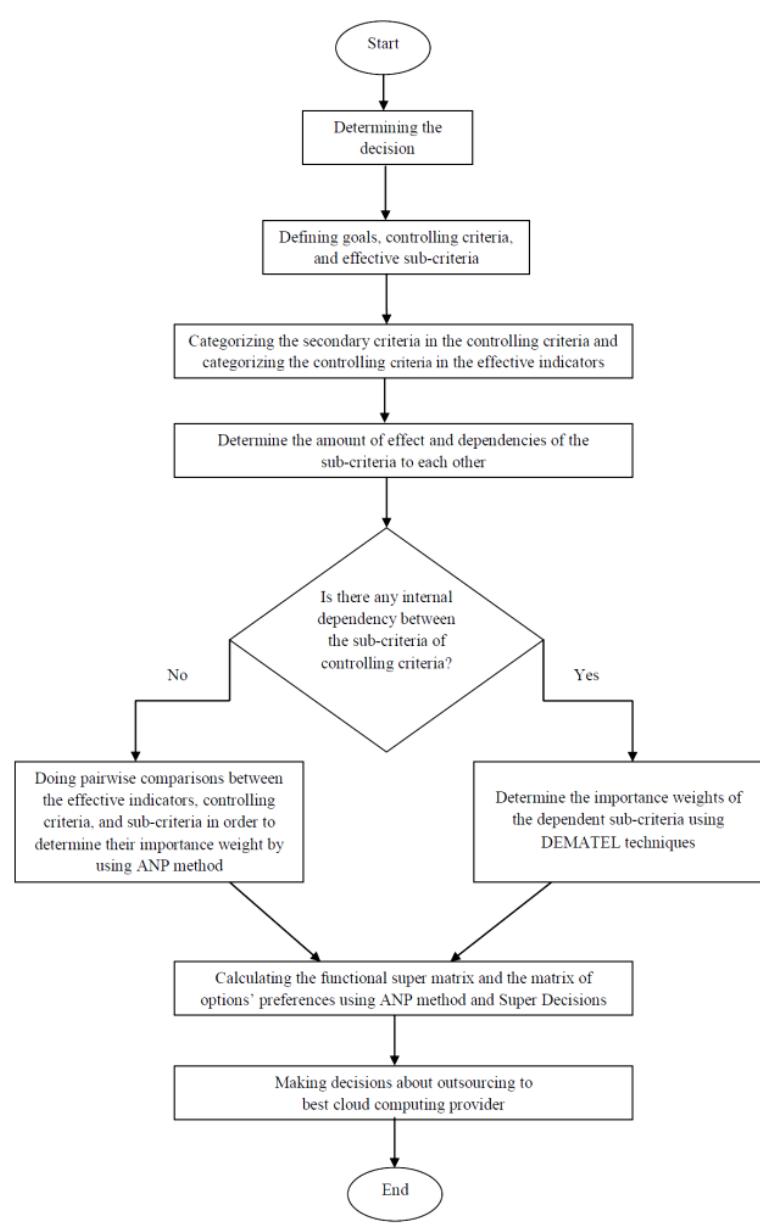

Figure 1. Process of the framework

Table 1. Criteria and sub-criteria and associated symbols

\begin{tabular}{|c|c|c|c|}
\hline Criteria & Symbol & Sub Criteria & Symbol \\
\hline \multirow{4}{*}{ Agility } & \multirow{4}{*}{$\mathrm{C} 1$} & Awareness/Visibility & S11 \\
\hline & & Flexibility & S12 \\
\hline & & Adaptability & S13 \\
\hline & & Capacity/Elasticity & S14 \\
\hline \multirow{2}{*}{ Costs } & \multirow{2}{*}{$\mathrm{C} 2$} & Acquisition & S21 \\
\hline & & On-Going & S22 \\
\hline \multirow{3}{*}{ Risk } & \multirow{3}{*}{$\mathrm{C} 3$} & Provider & S31 \\
\hline & & Compliance & S32 \\
\hline & & HR & S33 \\
\hline \multirow{4}{*}{ Security } & \multirow{4}{*}{$\mathrm{C} 4$} & Physical \& Environmental & S41 \\
\hline & & Communication\& Operation & S42 \\
\hline & & Access Control & S43 \\
\hline & & Data & S44 \\
\hline \multirow{4}{*}{ Quality } & \multirow{4}{*}{$\mathrm{C} 5$} & Serviceability & S51 \\
\hline & & Availability & S52 \\
\hline & & Functionality & S53 \\
\hline & & Effectiveness & S54 \\
\hline \multirow{2}{*}{ Capability } & \multirow{2}{*}{ C6 } & Function \#1 & S61 \\
\hline & & Function \#n & S62 \\
\hline
\end{tabular}




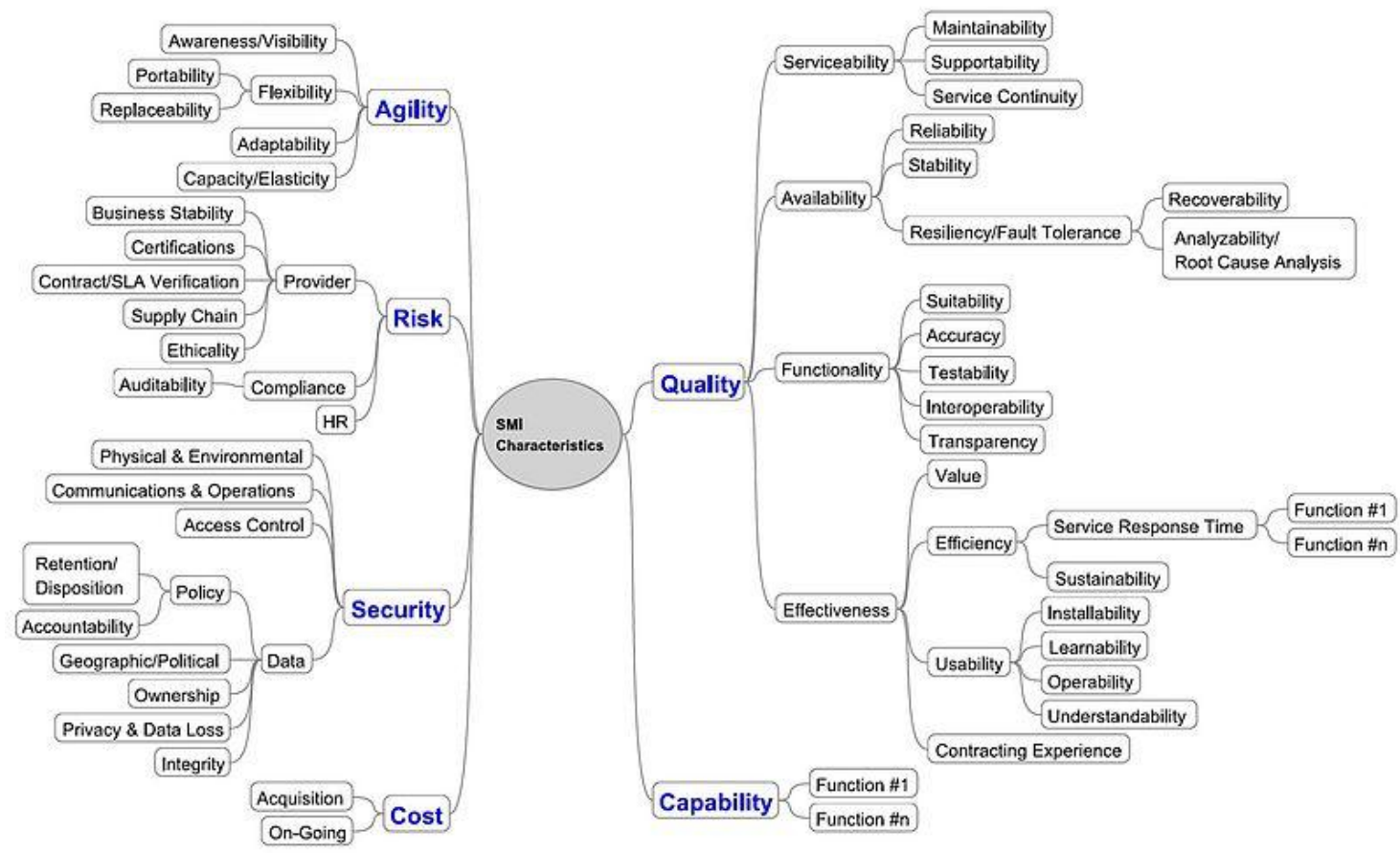

Figure 2. SMI attributes

Geometric mean is the most appropriate mathematics rule for combining assessments in AHP, because it maintains inverse property of pairwise comparison matrices [9]. In addition to considering each member of experts group's assessment, it will help to measure the assessment of the entire group for each pairwise comparison.

\subsection{Pairwise Comparison of Main Criteria Base on the Goal $\left(\mathbf{W}_{21}\right)$}

In this research, six main criteria as main decision criteria are selected. Therefore, at the first step criteria's pairwise comparison has been covered. The following table shows the result of performing pairwise comparison.

Table 2. Matrix of pairwise comparison of main criteria

$\begin{array}{ccccccccc} & \text { C1 } & \text { C2 } & \text { C3 } & \text { C4 } & \text { C5 } & \text { C6 } & \text { G } & \text { EV } \\ \text { C1 } & 1 & 0.240 & 0.247 & 0.149 & 0.209 & 1.431 & 0.372 & 0.051 \\ \text { C2 } & 4.169 & 1 & 2.187 & 0.574 & 1.046 & 3.728 & 1.653 & 0.226 \\ \text { C3 } & 4.043 & 0.457 & 1 & 0.871 & 2.702 & 3.438 & 1.570 & 0.214 \\ \text { C4 } & 6.722 & 1.741 & 1.149 & 1 & 2.952 & 4.762 & 2.396 & 0.327 \\ \text { C5 } & 4.789 & 0.370 & 0.370 & 0.339 & 1 & 3.245 & 0.947 & 0.129 \\ \text { C6 } & 0.699 & 0.268 & 0.291 & 0.210 & 0.308 & 1 & 0.390 & 0.053\end{array}$

As a result, Eigenvector $\mathrm{W}_{21}$ will be as follow:

$$
\mathbf{W}_{21}=\left(\begin{array}{c}
0.051 \\
0.226 \\
0.214 \\
0.327 \\
0.129 \\
0.053
\end{array}\right)
$$

The calculated inconsistency rate is: 0.074 which demonstrates performed pairwise comparisons is desirable.
Output of Super Decision software for prioritizing main criteria based on research goal is demonstrated in

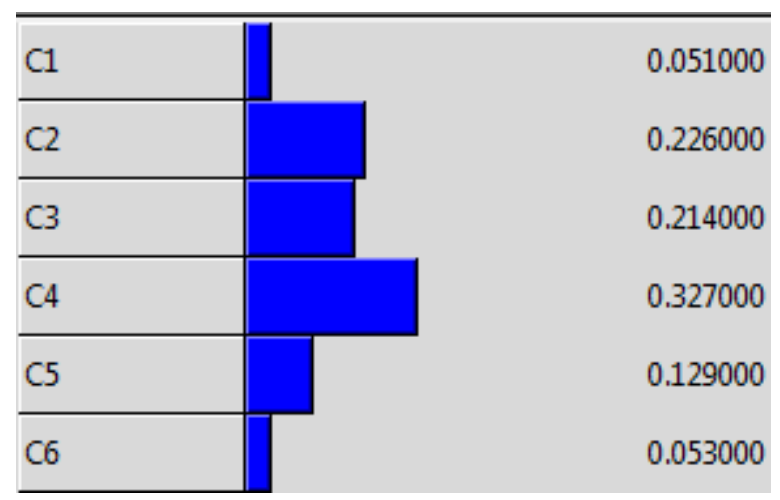

Figure 3. Prioritizing main criteria base on research goal with Super Decision software

As observed, based on research goal, criterion $\mathrm{C} 4$ with the normal weight of 0.327 has the most priority. Also Criteria $\mathrm{C} 2$ and $\mathrm{C} 3$ with the similar importance have second and third priority. Criterion $\mathrm{C} 5$ has forth priority and criteria $\mathrm{C} 1$ and $\mathrm{C} 6$ with similar weight of 0.051 and 0.053 have the least priority.

\section{2 pairwise Comparison of Main Criteria Interdependencies $\left(W_{22}\right)$}

In the next step, to get $\mathrm{W}_{22}$ super matrix, interdependencies for main criteria must be calculated. For this reason DEMATEL technique is used. Accordingly, experts are able to express their viewpoint of effects (direction and intensity) between criteria with more control. It is necessary to mention that this technique not only demonstrates initial effects but also is able to demonstrate the causal effect between each pair of criteria in the system by drawing influence map. 


\subsubsection{Calculating the Initial Direct-Relation Matrix (M)(average matrix)}

Each expert is asked to signify the grade to which he or she believes a criterion i affects criterion j. DEMATEL is based on three basic assumptions: First, A clear definition of the nature and characteristics of factors; second, grade ranging from $0,1,2,3$ and 4 representing the strength of the criteria which means 'No influence (0),' 'Low influence (1),' 'Medium influence (2),' 'High influence (3),' and 'Very high influence (4),' respectively; third, explanation of the relevance of various factors and management of implications. In the case of having group of experts, arithmetic mean will be used to calculate initial direct-relation matrix [10].

Table 3. Initial direct-relation matrix $(\mathrm{M})$ of main criteria

$\begin{array}{lcccccc} & \text { Agility } & \text { Costs } & \text { Risk } & \text { Security } & \text { Quality } & \text { Capability } \\ \text { Agility } & 0 & 2 & 1 & 2 & 2 & 2 \\ \text { Costs } & 3 & 0 & 3 & 3 & 4 & 4 \\ \text { Risk } & 1 & 1 & 2 & 1 & 2 & 2 \\ \text { Security } & 2 & 4 & 3 & 3 & 3 & 1 \\ \text { Quality } & 1 & 3 & 1 & 2 & 2 & 1 \\ \text { Capability } & 1 & 3 & 1 & 1 & 1 & 0\end{array}$

\subsubsection{Calculation of the Normalized Initial}

$$
\text { Direct-Relation Matrix ( } N=\frac{M}{k} \text { ) }
$$

The normalized initial direct-relation matrix $\mathrm{N}$ is obtained by normalizing the average matrix $\mathrm{M}$ in the following method:

$$
\begin{aligned}
& k=\max \left(\max _{1 \leq i \leq n} \sum_{j=1}^{n} a_{i j}, \max _{1 \leq j \leq n} \sum_{i=1}^{n} a_{i j}\right) \\
& N=\frac{M}{k}
\end{aligned}
$$

While the sum of each row $\mathrm{j}$ of matrix $\mathrm{M}$ represents the total direct effects that criterion $\mathrm{i}$ gives to the other criteria,

$$
\max _{1 \leq i \leq n} \sum_{j=1}^{n} a_{i j}
$$

represents the total direct effects of the criterion with the most direct effects on others. Similarly, while the sum of each column i of matrix $M$ represents the total direct effects received by criterion $\mathrm{i}, \max _{1 \leq j \leq n} \sum_{i=1}^{n} a_{i j}$ represents the total direct effects received of the factor that receives the most direct effects from others. The matrix $\mathrm{N}$ is obtained by dividing each element of $\mathrm{M}$ by the scalar $\mathrm{k}$. Note that each element $n_{i j}$ of matrix $\mathrm{N}$ is between zero and less than 1. Based on Matrix M, scalar $\mathrm{k}$ is equal to 17 and normalized matrix is demonstrated as follows:

Table 4. Normalized matrix $\mathbf{N}$ for main criteria

$\begin{array}{lcccccc} & \text { Agility } & \text { Costs } & \text { Risk } & \text { Security } & \text { Quality } & \text { Capability } \\ \text { Agility } & 0.000 & 0.118 & 0.059 & 0.118 & 0.118 & 0.118 \\ \text { Costs } & 0.176 & 0.000 & 0.176 & 0.176 & 0.235 & 0.235 \\ \text { Risk } & 0.059 & 0.059 & 0.118 & 0.059 & 0.118 & 0.118\end{array}$

$\begin{array}{lcccccc}\text { Security } & 0.118 & 0.235 & 0.176 & 0.176 & 0.176 & 0.059 \\ \text { Quality } & 0.059 & 0.176 & 0.059 & 0.118 & 0.118 & 0.059 \\ \text { Capability } & 0.059 & 0.176 & 0.059 & 0.059 & 0.059 & 0.000 \\ \text { 6.2.3 Computing the Total Relation Matrix } & \end{array}$

A continuous reduction of the indirect effects of problems along the powers of matrix $\mathrm{N},\left(\right.$ e.g., $\left.\mathrm{N}^{2}, \mathrm{~N}^{3}, \ldots, \mathrm{N}^{\infty}\right)$, guarantees convergent solutions to the matrix inverse. The total relation matrix $\mathrm{T}$ is an $\mathrm{n} \times \mathrm{n}$ matrix and is defined as follow:

$$
T=N \times(I-N)^{-1}
$$

Note that $\lim _{\mathrm{m} \rightarrow \infty} \mathrm{N}^{\mathrm{m}}=[0]_{\mathrm{n} \times \mathrm{n}}$ and

$\lim _{m \rightarrow \infty}\left(I+N+N^{2}+N^{3}+\cdots+N^{\infty}\right)=(I-N)^{-1}$, where 0 is the $\mathrm{n} x \mathrm{n}$ null matrix and $\mathrm{I}$ is the $\mathrm{n} \times \mathrm{n}$ identity matrix.

Table 5. Total relation matrix $T$ of main criteria

$\begin{array}{lcccccc} & \text { Agility } & \text { Costs } & \text { Risk } & \text { Security } & \text { Quality } & \text { Capability } \\ \text { Agility } & 0.152 & 0.343 & 0.255 & 0.329 & 0.364 & 0.287 \\ \text { Costs } & 0.402 & 0.396 & 0.485 & 0.517 & 0.627 & 0.500 \\ \text { Risk } & 0.185 & 0.260 & 0.286 & 0.240 & 0.331 & 0.268 \\ \text { Security } & 0.382 & 0.619 & 0.527 & 0.555 & 0.623 & 0.381 \\ \text { Quality } & 0.233 & 0.425 & 0.285 & 0.364 & 0.406 & 0.265 \\ \text { Capability } & 0.186 & 0.343 & 0.224 & 0.238 & 0.271 & 0.159 \\ \text { 6.2.4 } & \text { Obtaining the Network-Relations-Map }\end{array}$

In order to clarify the structural relation between criteria while balancing the complexity of the system to a convenient degree, it is essential to set a threshold value $\mathrm{p}$ to extract some insignificant effects in matrix $\mathrm{T}$. As long as each criterion of matrix $\mathrm{T}$ gives information on how one criterion affects another, it is essential for the management group (decisionmakers) to set a threshold value to decrease the complexity of the structural relation model implied in matrix T. Therefore, only some criteria, which's effect in matrix $\mathrm{T}$ is greater than the threshold value, must be chosen and presented in an network-relations-map (NRM) [11].

In this research, the threshold value has been calculated equal to 0.35 . While the threshold value has been calculated, the final result can be demonstrated in an NRM as below:

Table 6. NRM of main criteria

$\begin{array}{lcccccc} & \text { Agility } & \text { Costs } & \text { Risk } & \text { Security } & \text { Quality } & \text { Capability } \\ \text { Agility } & 0 & 0 & 0 & 0 & 0.364 & 0 \\ \text { Costs } & 0.402 & 0 & 0.485 & 0.517 & 0.627 & 0.500 \\ \text { Risk } & 0 & 0 & 0 & 0 & 0 & 0 \\ \text { Security } & 0.382 & 0.619 & 0.527 & 0 & 0.623 & 0.381 \\ \text { Quality } & 0 & 0.425 & 0 & 0.364 & 0 & 0 \\ \text { Capability } & 0 & 0 & 0 & 0 & 0 & 0\end{array}$

The cluster interdependencies map is demonstrated below. 


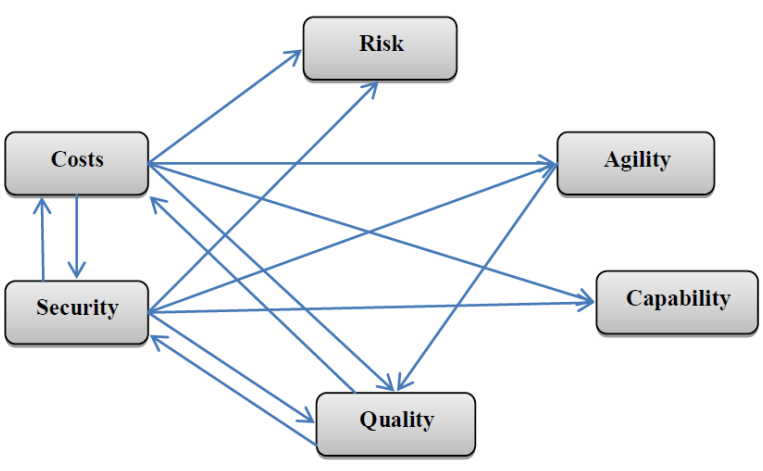

Figure 4. Cluster interdependencies map

In regard to NRM for criteria causal relation diagram is produced as demonstrated in Table 7:

Table 7. Causal diagram for main criteria

$\begin{array}{lcccc} & \mathrm{D} & \mathrm{R} & \mathrm{D}+\mathrm{R} & \mathrm{D}-\mathrm{R} \\ \text { Agility } & 1.729 & 1.540 & 3.269 & 0.189 \\ \text { Costs } & 2.927 & 2.386 & 5.312 & 0.541 \\ \text { Risk } & 1.569 & 2.061 & 3.630 & -0.491 \\ \text { Security } & 3.088 & 2.243 & 5.331 & 0.845 \\ \text { Quality } & 1.978 & 2.622 & 4.600 & -0.644 \\ \text { Capability } & 1.420 & 1.859 & 3.280 & -0.439\end{array}$

The sum of indices in each row (D) denotes degree of effect, given by that criterion on other criteria in the system. In this case Security has the most effect given. After that Costs with approximately equivalent effect given is in second place. Quality and Agility criteria are also having equivalent effect given and placed in lower level and after them Risk and Capability.

$$
D=\left[D_{i}\right]_{n \times 1}=\sum_{j=1}^{n} t_{i j}
$$

The sum of each column (R) denotes degree of effect, received by that criterion on other criteria in the system. Based on this Quality hast the most effect received by other criteria. Agility criterion has the least effect received from other criterion.

$$
R=\left[R_{j}\right]_{1 \times n}^{\prime}=\left(\sum_{i=1}^{n} t_{i j}\right)_{1 \times n}^{\prime}
$$

The horizontal axis vector $(\mathrm{D}+\mathrm{R})$ is called Prominence, which specifies the degree of relative importance of each criterion. In other words, if the value of $D+R$ for particular criterion be higher, that criterion has more interaction with other criteria in the system. Based on this, Cost and Security criteria are having the most interaction with other criteria that are covered. Also Agility and Capability criteria are having the least interaction with other criteria in the system.

The vertical axis vector $(D-R)$ called relation and may assign criteria in cause and effect groups. Generally, when $(D-R)$ is positive, that particular is a net causer, and when negative, is a net receiver. In this model Agility, Cost and
Security are the causer criteria and Risk, Quality and Capability are receiver.

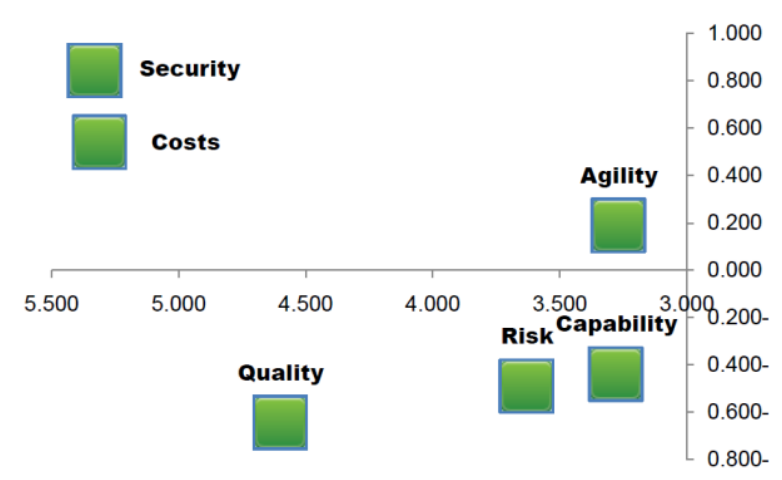

Figure 5. Scatter graph of DEMATEL for main criteria

\subsection{Pairwise Comparison of Sub- Criteria $\left(\mathbf{W}_{32}\right)$}

In the third step pairwise comparison of SMI's sub-criteria has been covered. In each step pairwise comparison are applied to sub-criteria related to each main criterion of matrix.

\subsubsection{Pairwise Comparison of Agility Sub- Criteria}

Based on acquired result, index S14 with weight 0.369 has the highest priority. Index S13 is in second place and index S12 is in third place. After all index S11 has the lowest priority. Since, inconsistency ratio of applied comparisons is 0.074 , acquired results are reliable.

\subsubsection{Pairwise Comparison of Cost Sub-Criteria}

The result of Cost's sub-criteria pairwise comparison demonstrates that based on acquired result; index S21 with normal weight of 0.723 has higher priority than Index S22. Additionally, in comparison of two criteria is always equal to 0 , therefore acquired results are reliable.

\subsubsection{Pairwise Comparison of Risk Sub-Criteria}

For the Risk's sub-criteria pairwise comparison, index S31 has the highest priority. Index S32 is in second place and index S33 has the lowest priority. Since, inconsistency ratio of applied comparisons is 0.002 , acquired results are reliable.

\subsubsection{Pairwise Comparison of Security Sub- Criteria}

The result of Security's sub-criteria pairwise comparison shows that index S44 is the most important index among Security's sub-criteria and has the highest priority. Indexes S43 and S41 are having the next high priority and index S42 has the lowest priority. Since, inconsistency ratio of applied comparisons is 0.087 , acquired results are reliable.

\subsubsection{Pairwise Comparison of Quality Sub- Criteria}

The result of Quality's sub-criteria pairwise comparison shows that index S52 is the most important index among Quality's sub-criteria and has the highest priority. Indexes S53 and S51 are having the next high priority and index S54 
has the lowest priority. Since, inconsistency ratio of applied comparisons is 0.015 , acquired results are reliable.

\subsubsection{Pairwise Comparison of Capability Sub- \\ Criteria}

According to experts' opinion, both index of Capability criterion have the equal importance. This result is clearly observed in following table and figure. Additionally, in comparison of two criteria is always equal to 0 , therefore acquired results are reliable.

\subsection{Pairwise Comparison of Sub- Criteria Interdependencies $\left(\mathbf{W}_{33}\right)$}

For reflecting the interdependencies between sub-criteria, DEMATEL technique is used. As we did before, four steps should be performed: at first Initial Direct-Relation Matrix (M) has been calculated for sub-criteria. Because viewpoint of group of expert are used, arithmetic mean will be used to calculate the matrix. At the second step initial direct relation matrix must be normalized. Based on matrix $\mathrm{M}$, scalar $\mathrm{k}$ is equal to 35 for sub-criteria. Later, at the third step total relation matrix $\mathrm{T}$ has been calculated. Finally, at forth step, In order to determine network-relation-map (Table 8), threshold value must be calculated as explained in previous part. With this technique slight relation can be skipped. In this part, threshold value has been calculated equal to 0.147. As long as the threshold value has been calculated, the final result can be shown in an NRM demonstrated in Figure 6.

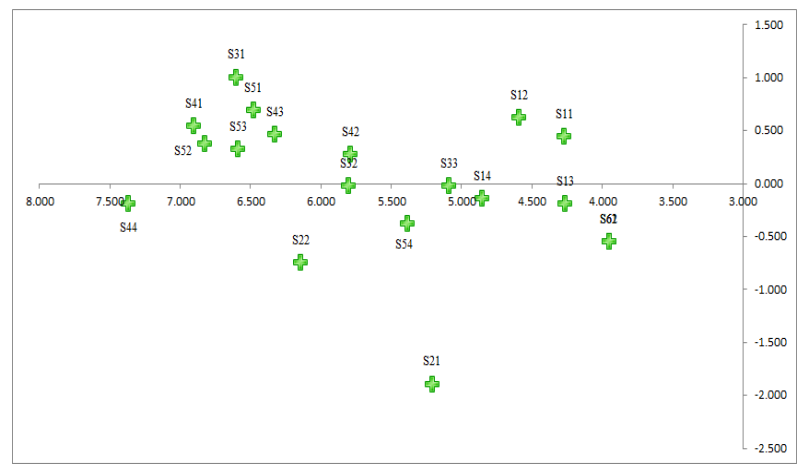

Figure 6. Scatter graph of DEMATEL for sub-criteria

Table 8. NRM for sub-criteria

\begin{tabular}{|c|c|c|c|c|c|c|c|c|c|c|c|c|c|c|c|c|c|c|c|}
\hline & S11 & $\mathrm{S} 12$ & S13 & S14 & S21 & $\mathrm{S} 22$ & S31 & S32 & S33 & S41 & S42 & S43 & S44 & S51 & S52 & S53 & S54 & S61 & S62 \\
\hline S11 & & & & & 0.173 & 0.169 & & & & 0.162 & & & 0.178 & & & & & & \\
\hline $\mathrm{S} 12$ & & & & & 0.184 & 0.180 & 0.158 & & & 0.170 & & & 0.164 & & & & & & \\
\hline S13 & & & & & 0.155 & 0.151 & & & & & & & & & & & & & \\
\hline S14 & & & & & 0.171 & 0.168 & & & & 0.159 & & & 0.148 & & & & 0.152 & & \\
\hline \multicolumn{20}{|l|}{ S 21} \\
\hline S22 & & & & 0.150 & 0.162 & & & & & 0.148 & & & 0.169 & 0.164 & 0.177 & 0.173 & 0.165 & & \\
\hline S31 & & 0.163 & 0.176 & 0.188 & 0.246 & 0.212 & & 0.213 & 0.193 & 0.227 & 0.204 & 0.215 & 0.286 & 0.211 & 0.228 & 0.223 & 0.181 & 0.148 & 0.148 \\
\hline S32 & & & & & 0.198 & 0.194 & 0.167 & & & 0.157 & & 0.176 & 0.234 & & 0.159 & 0.184 & 0.172 & & \\
\hline S33 & & & & & 0.180 & 0.177 & & & & & & 0.162 & 0.215 & & & & & & \\
\hline S41 & & & & 0.186 & 0.241 & 0.235 & 0.201 & 0.211 & 0.190 & & 0.202 & 0.214 & 0.282 & 0.209 & 0.254 & 0.193 & 0.179 & & \\
\hline S42 & & & & & 0.206 & 0.202 & & 0.155 & & 0.193 & & 0.184 & 0.243 & 0.181 & 0.196 & 0.163 & 0.150 & & \\
\hline S43 & & & & & 0.224 & 0.220 & 0.160 & 0.198 & 0.179 & 0.209 & 0.189 & & 0.292 & 0.196 & 0.212 & 0.207 & 0.165 & & \\
\hline S44 & & & & 0.151 & 0.234 & 0.229 & 0.169 & 0.230 & 0.185 & 0.243 & 0.196 & 0.260 & & 0.203 & 0.220 & 0.214 & 0.173 & & \\
\hline S51 & & & & 0.181 & 0.234 & 0.228 & 0.196 & 0.204 & 0.157 & 0.217 & 0.196 & 0.205 & 0.247 & & 0.247 & 0.215 & 0.202 & & \\
\hline S52 & & & 0.167 & 0.153 & 0.233 & 0.228 & 0.197 & 0.203 & 0.158 & 0.215 & 0.195 & 0.204 & 0.246 & 0.202 & & 0.214 & 0.201 & 0.170 & 0.170 \\
\hline S53 & 0.147 & & & 0.149 & 0.226 & 0.221 & 0.189 & 0.197 & 0.180 & 0.210 & 0.188 & 0.173 & 0.265 & 0.168 & 0.184 & & 0.194 & 0.164 & 0.164 \\
\hline S54 & & & & & 0.179 & 0.175 & & & & & & & 0.158 & & 0.168 & 0.166 & & & \\
\hline \multicolumn{20}{|l|}{ S61 } \\
\hline S62 & & & & & & & & & & & & & & & & & & & \\
\hline
\end{tabular}

\subsection{The Final Priority of SMI Criteria with ANP Technique}

Calculation of unweighted super-matrix, weighted supermatrix and limit super-matrix:

To reach the entire priorities in a system with mutual effect, internal priority vectors (calculated W's) must be inserted in the proper column of a matrix. As a result, a supermatrix (partitioned matrix) will be acquire, which demonstrates relations between clusters in the system. In other words, a supermatrix is a matrix of relation between network elements, which is calculated based on priority vectors of those relations. This matrix formulates a framework for determining relative importance of criteria after all pairwise comparisons. In consideration of determined relation in this research, the supermatrix is as below: 


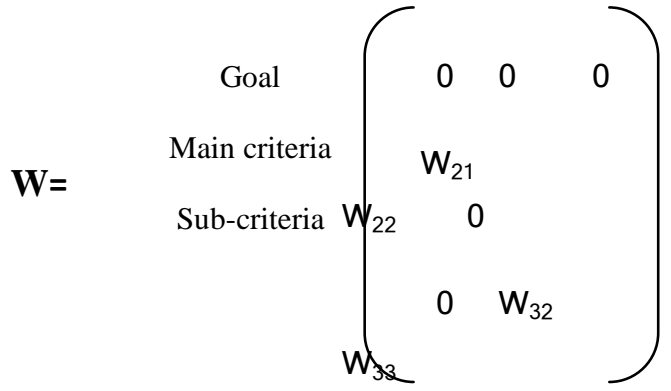

Structure of initial unweighted supermatrix

In this super-matrix:

Vector $\mathrm{W}_{21}$ represents the effect of goal on each main criterion.

Vector $\mathrm{W}_{22}$ represents the main criteria interdependencies' Pairwise Comparison.

Vector $\mathrm{W}_{32}$ represents the effect of each subcriterion on other sub-criteria

Vector $\mathrm{W}_{33}$ represents the sub-criteria interdependencies' pairwise comparison.

The 0 indices represent the affectless of criteria in that particular place.

With using normalization concept, unweighted supermatrix is converted to weighted supermatrix (normal). In weighted super-matrix, sum of all indices of all columns is equal to 1 .

In the next step, limit supermatrix is calculated. Limit supermatrix is calculated by repeating exponentiation until all indices of supermatrix get closer to each other. In this situation all indices will be equal to 0 and only those indices related to sub-criteria will be a number that repeats in all rows of those particular sub-criteria.

\section{RESULTS}

At last and based on calculation performed by Super Decision software, the output for final priority of criteria and subcriteria is illustrated below:

To select the best alternative, after obtaining the weight of each criterion, in the first step each alternative should be pairwise compared based on each criterion.

Table 9. Final priority of all factors in the model by ANP

\begin{tabular}{|c|l|c|c|c|c|}
\hline $\begin{array}{c}\text { Sub } \\
\text { Criteria }\end{array}$ & \multicolumn{1}{|c|}{ name } & Total & Normal & Ideal & Rank \\
\hline S31 & Provider & 0.1242 & 0.1242 & 1 & 1 \\
\hline S52 & Availability & 0.1014 & 0.1014 & 0.8166 & 2 \\
\hline S53 & Functionality & 0.099 & 0.099 & 0.7969 & 3 \\
\hline S44 & Data & 0.0901 & 0.0901 & 0.7251 & 4 \\
\hline S41 & Physical\& & 0.089 & 0.089 & 0.7163 & 5 \\
\hline S51 & Serviceability & 0.0854 & 0.0854 & 0.6871 & 6 \\
\hline S43 & Access Control & 0.0835 & 0.0835 & 0.6724 & 7 \\
\hline
\end{tabular}

\begin{tabular}{|c|c|c|c|c|c|}
\hline S42 & $\begin{array}{l}\text { Communication\& } \\
\text { operation }\end{array}$ & 0.0762 & 0.0762 & 0.6132 & 8 \\
\hline $\mathrm{S} 32$ & Compliance & 0.0564 & 0.0564 & 0.4544 & 9 \\
\hline S22 & On-Going & 0.0446 & 0.0446 & 0.3593 & 10 \\
\hline S33 & HR & 0.035 & 0.035 & 0.2815 & 11 \\
\hline $\mathrm{S} 12$ & Flexibility & 0.0329 & 0.0329 & 0.2648 & 12 \\
\hline S54 & Effectiveness & 0.0218 & 0.0218 & 0.1758 & 13 \\
\hline S14 & Capacity/Elasticity & 0.0213 & 0.0213 & 0.1713 & 14 \\
\hline S11 & Awareness/Visibility & 0.0191 & 0.0191 & 0.1535 & 15 \\
\hline $\mathrm{S} 21$ & Acquisition & 0.0106 & 0.0106 & 0.0854 & 16 \\
\hline $\mathrm{S} 13$ & Adaptability & 0.0037 & 0.0037 & 0.0295 & 17 \\
\hline S61 & Function \#1 & 0.0029 & 0.0029 & 0.0235 & 18 \\
\hline S62 & Function \#n & 0.0029 & 0.0029 & 0.0235 & 19 \\
\hline
\end{tabular}

As an example pairwise comparison of alternatives based on provider risks is shown. A1 on compare of A3 gets 4 point and $\mathrm{A} 2$ in compare of $\mathrm{A} 3$ gets 9 point. When all comparisons are done, data must be transferred to a matrix called pairwise comparison matrix.

Table 10. Pairwise comparison of alternatives

$\begin{array}{cccc}\text { Availability } & \text { A1 } & \text { A2 } & \text { A3 } \\ \text { A1 } & 1 & 1 / 4 & 4 \\ \text { A2 } & 4 & 1 & 9 \\ \text { A3 } & 1 & 1 / 9 & 1\end{array}$

Next step is computing priorities. As explained before, for this reason normalizing concept will be used. After normalizing, weight of each alternative based on particular criterion will be acquired. Value gained from this computation form a priority column that called eigenvector.

In the last, the weights obtained in the previous step, will be used to best selection. Desirability Index will be used to determine best alternative. The selection of best provider depends on the outcome of desirability index. The computation of the DIs is the derivations of the weights based on the pairwise comparison of all under the different criteria.

$$
\begin{aligned}
\square \square_{\square}=\sum_{\square=1}^{\square} \square_{\square \square} & =\sum_{\square=1}^{\square} \square_{\square} \square_{\square \square}, \quad \forall \square, \square \\
& =1,2, \ldots, \square,
\end{aligned}
$$

- $\quad D I_{i}$ : Desirability Index for alternative $i$

$$
\begin{aligned}
& \text { - } \quad S_{i j} \text { : Weight of alternative } \mathrm{i} \text { with respect to criterion } j \\
& \text { - } \quad R_{j} \text { : Relative weight of sub-criteria } R \\
& \text { - } \quad W_{i j} \text { : Relative weight of alternative } i \text { with respect to } \\
& \text { sub-criterion } j
\end{aligned}
$$

An alternative which has the most $D I$ is the best alternative. As a result $A^{*}$ set is defined below:

$$
A^{*}=\left\{A_{i} \mid D I_{i}=\text { Maximum } k=1,2, \ldots, n\left(D I_{k}\right)\right\}
$$

\section{CONCLUSION AND FUTURE}


Cloud computing has become an important paradigm for outsourcing various IT needs of the organization. Currently, there are many cloud providers who are offering different cloud services with different QoS and SLAs. The implementation of a cloud computing strategy might be a risky attempt for the top management as it involves financial and operational aspects, which can determine the performance of the organization in the long term. There are some strategies to cope with these risks, but one of the most important issues for top management is evaluation of determined criteria to understand priorities, then comparing various cloud providers' offering and conclude relative strengths and impacts of them. Selecting a provider to handle risk is multi criteria decision problem. Many criteria and sub-criteria are relevant and have interdependencies. Using ANP technique in integrating both quantitative as well as the qualitative characteristics, and their interdependencies could identify the suitable alternative based on the scores. In this research to select best provider, integrating ANP and DEMATEL is proposed to demonstrate significance, importance and interdependencies of determined criteria and then evaluate the suitable cloud provider.

For the future research, the difficulty can be explained by other MCDM methods, and the solutions can be compared. Also ANP under fuzzy environment can be utilized for provider selection process, and intelligent programs to assess solutions automatically can be developed. Another suggestion is to consider other risks, such as political/social risks and behavioral risks. Furthermore, focus on other alternatives for eliminating or reducing risks can be exposed in a more completed network.

\section{ACKNOWLEDGMENTS}

We would like to use this opportunity to thank the respondents of the interviews and surveys that were conducted for this study. By sharing their experience with the discussed topics, they have greatly contributed to the final outcome of the study.

\section{REFERENCES}

[1] Winkler, Vic J.R. Securing the Cloud. Waltham, MA, USA : Elsevier, 2011. ISBN: 978-1-59749-592-9.

[2] NIST. Challenging Security Requirement for US Government Cloud Computing Adoption. Gaithersburg,
MD, USA : National Institue of Standards and Tehcnology, 2011.

[3] Cloud Service Measurement Initiative Consortium. Service Measurement Index Version 1.0. Moffett Field, CA ,USA : Carnegie Mellon University Silicon Valley, 2011.

[4] SMICloud: A Framework for Comparing and Ranking Cloud Services. Garg, Saurabh Kumar, Versteeg, Steve and Buyya, Rajkumar. Melbourne, Australia : IEEE, 2011, Vol. 4. DOI 10.1109/UCC.2011.36.

[5] Using a multi-criteria decision making approach (ANPTOPSIS) to evaluate suppliers in Iran's auto industry. Shahroudi, K and Rouydel, H. 2, s.l. : International Journal of Applied Operational Research, 2012, Vol. 2.

[6] The Risk Management Strategy of Applying Cloud Computing. Chiang, Fan $\mathrm{Ku}$ and Tien-Chun, Chen. 9, s.l. :

[7] International Journal of Advanced Computer Science and Applications,, 2012, Vol. 3.

[8] Cloud Commons. Introducing the Service Measurement Index . Cloud Commons. [Online] Cloud Commons, 2011. http://www.cloudcommons.com/web/cc/SMIintro.

[9] Wikipedia. Service Measurement Index. Wikipedia. [Online] Wikipedia, 2012 http://en.wikipedia.org/wiki/Service_Measurement_Inde $\mathrm{x}$.

[10] Decision making with the analytic hierarchy process. Saaty, Thomas L. 1, Pittsburgh, PA ,USA : International Journal of Services Sciences, 2008, Vol. 1.

[11] A Causal Decision Making Model for Knowledge Management Capabilities to Innovation Performance in Taiwan's High-Tech Industry. Chang, Hung Fan and Tzeng, Gwo Hshiung. 4, Hsinchu City, Taiwan : Hsinchu City 300, Taiwan, 2010, Vol. 5.

[12] Evaluating intertwined effects in e-learning programs: A novel hybrid MCDM model based on factor analysis and DEMATEL. Tzeng, Gwo Hshiung, Chiang, Cheng Hsin and Li, Chung Wei. 4, Hsinchu, Taiwan : Elsevier Inc, 2007, Vol. 32. doi:10.1016/j.eswa.2006.02.004 